Open Access

\title{
Purification and Structural Analysis of Surfactin Produced by Endophytic Bacillus subtilis EBS05 and its Antagonistic Activity Against Rhizoctonia cerealis
}

\author{
Cai-Yi Wen ${ }^{1,2}$, Zhi-Gang Yin ${ }^{2}$, Kai-Xuan Wang ${ }^{2}$, Jian-Guang Chen ${ }^{2}$ and Shun-Shan Shen ${ }^{2 *}$ \\ ${ }^{\text {I}}$ Post-doctoral Work Station, Fujian Agriculture and Forestry University, Fuzhou 350002, China \\ ${ }^{2}$ College of Plant Protection, Henan Agricultural University, Zhengzhou, Henan 450002, China \\ (Received on March 9, 2011; Revised on July 22, 2011; Accepted on August 19, 2011)
}

Bacillus subtilis EBS05, an endophytic bacteria strain isolated from a medicinal plant Cinnamomum camphor, can produce antagonistic compounds that effectively inhibit plant pathogenic fungi. The greenhouse experiments showed that wheat sharp eyespot disease (WSED) was reduced by $91.2 \%, 88.2 \%$ and $43.0 \%$ after the treatment with fermentation broth, bacteria-free filter and a fungicide fludioxonil, respectively. The culture broth of strain EBS05 can more effectively control WSED than can fludioxonil. The fermentation broth and bacteria-free filter ability to suppress WSED was not significantly different, suggesting that an active secreted substance played a major role in controlling WSED. Separation and purification of the active compounds was carried out by serial processes, including hydrochloric acid (pH 2.0) treatment, methanol extraction and Sephadex LH-20 column chromatography, silica gel column chromatography and reverse-phase high-pressure liquid chromatography (HPLC), respectively. The purified compounds, one of active peaks in the HPLC spectrum, were obtained from the collection. Analysis of the chemical structures by time-of-flight mass spectrometry (TOF-MS) and electrospray ionization mass spectrometry/mass spectrometry (ESI-MS/ MS) showed that the active substances produced by the endophytic bacteria EBS05 are mixture of the $\beta$-hydroxy-C12 C15-Leu ${ }^{7}$ surfactin $A$ isomers with 1035.65 Da, 1021.64 Da, 1007.63 Da and 993.65 Da molecular weights, respectively.

Keywords : antimicrobial activity, Bacillus subtilis, plant endophyte, surfactin

Endophytes are specific groups of microorganisms residing inside healthy plant tissue without any discernible infectious symptoms (Hallmann et al., 2003; Ryan et al., 2008; Wilson, 1995). They may contribute to their host plant by producing metabolite substances that play important roles

\footnotetext{
*Corresponding author.

Phone) +86-371-6355-8170, FAX) +86-371-6355-8170

E-mail)shen0426@163.com
}

in promoting plant growth and plant disease management (Bacon and Hinton, 1999; Misaghi and Donndelinger, 1990; Pleban et al., 1995; Sturz et al., 1997). As a potential source of novel natural products for medicinal, agricultural, and industrial uses, endophytes could provide a wide variety of structurally unique bioactive natural products, such as alkaloids, steroids, terpenoids, quinones, flavonoids, peptides, aliphatic compounds, chlorinated metabolites, and others (Tan and Zou, 2001). Novel antibiotics, antimycotics, antinematodes, immunosuppressants, and anticancer compounds have been reported from endophytic metabolites as well (Kowall et al., 1998; Strobel et al., 2004; Sturz and Kimpinski, 2004). Cinnamomum camphora, a well-known landscape and medicinal plant, has been used for many centuries as a culinary spice, a component of incense, a medicine, a bug-repellent and a flea-killing substance. Chemical substances in the plant are valuable antiseptics and medications for treating diarrhea, inflammation, itching, and nervous conditions (http://www.floridata.com/ref/ C/cinn_cam.cfm). Previous studies have shown that some endophytes can excrete antimicrobial compounds that are similar to endogenous metabolites of their host plant, and many biological active substances produced by endophytes are relatively new to us (Schulz et al., 2002; Strobel, 2003; Sun et al., 2006). Therefore, the camphor tree, collected from Henan Agricultural University campus, was selected as a source of endophytic microorganisms.

Surfactin is an amphiphilic cyclic lipoheptapeptide biosurfactant produced by various strains of Bacillus subtilis (Kowall, 1998). It shows significant inhibitory activity against phytopathogenic fungi, bacteria, viruses and mycoplasma (Nissen-Meyer and Nes, 1997; Phae et al., 1990). In general, surfactin is a mixture of isoforms that differ slightly in their physicochemical properties and biological activity due to variations in the chain length and branching of their hydroxy fatty acid component and substitutions of the amino acid components of the peptide ring (Grangemard et al., 1997). These variations depend on the specific $B$. subtilis strain and the nutritional and cultural conditions under which the strains are grown (Peypoux and Michel, 
1992). There are three different types of surfactins, A, B, and $\mathrm{C}$, which are classified according to the differences in their amino acid sequences (Rodrigues, 2006).

Previously, we demonstrated that endophytic B. subtilis EBS05 has many potential properties as a biological control agent, such as wide-spectrum antibiotic activity against tobacco mosaic virus and various phypathogenic fungi, as well as a tolerance of acid, alkali, salt and heat (Wen et al., 2009). In this paper, we report the purification process and the lipopeptide structure analysis of the biosurfactant produced by endophytic $B$. subtilis EBS05, which was isolated from $C$. camphora. The biosurfactant was structurally identified as surfactin A. In addition, the antagonistic activity of surfactin A against Rhizoctonia cerealis was investigated.

\section{Materials and Methods}

Isolation of endophytic bacteria EBS05. C. camphora leaves and stems were collected from the Henan Agricultural University campus. The surface sterilization was conducted according to the procedure of Mendes et al. (2007) with some modifications. The samples were washed immediately with tap water to remove the attached dust and soil, and then sterilized successively with $75 \%$ ethanol for $1 \mathrm{~min}$ and $5 \%$ sodium hypochlorite for $5 \mathrm{~min}$. After being rinsed three times with sterilized distilled water, the outer tissues of the samples were removed with a sterilized knife blade, and the remainders were cut into $0.5-\mathrm{cm}-$ long fragments. The fragments were treated with $70 \%$ ethanol for 10 seconds and rinsed three times with sterilized distilled water. The rinsed fragments were vertically halved and incubated on YPDA medium (yeast peptone dextrose agar: yeast extract $3 \mathrm{~g}$, peptone $0.6 \mathrm{~g}$, dextrose $3 \mathrm{~g}$, agar $16 \mathrm{~g}$, distilled water 1 liter, $\mathrm{pH} 7.2$ ) at $28^{\circ} \mathrm{C}$ until the colonies appeared around the segments. The isolates were purified by streak culturing, and the distinct colonies were subcultured on YPDA slants at $28^{\circ} \mathrm{C}$. At the same time, isolates were stored at $-80^{\circ} \mathrm{C}$ in cryogenic tubes containing $30 \%$ glycerol until used. In order to evaluate the effectiveness of the above sterile process, a similar procedure without surface sterilization was performed as a negative control and aliquots of $0.1 \mathrm{ml}$ of the last rinsed water were inoculated on YPDA medium as a positive control.

Greenhouse experiments. Greenhouse pot experiments were conducted under standard greenhouse conditions at $28-32^{\circ} \mathrm{C}$. Treated and control wheat seedlings (cv. Zhengmai93) were planted in the greenhouse in polypropylene boxes pots (10 $\mathrm{cm}$ high, $12 \mathrm{~cm}$ diameters) containing raw sandy loam soil that had been artificially infested with the pathogens $R$. cerealis (Inbar and Chet,
1991) by $50 \mathrm{mg}$ of sclerotia with $1 \mathrm{~kg}$ of soil (Henis, 1984). Treatment groups included (1) seeds were coated by fludioxonil before they were sown. (2) EBS05 fermentation broth (cell densities, $10^{8} \mathrm{cfu} / \mathrm{ml}$ ) applied on the soil surface of the pots (15 $\mathrm{ml}$ per pot) when the seeds were sown and covered with $2 \mathrm{~cm}$ of soil. (3) $15 \mathrm{ml}$ of filtrate (bacteria-free culture supernatant sterilized at $121^{\circ} \mathrm{C}, 0.15 \mathrm{MPa}$ for 15 min) from EBS05 ferment broth applied on the soil surface of the pots when the seeds were sown and covered with 2 $\mathrm{cm}$ of soil. Control plants were grown in pots treated with $15 \mathrm{ml}$ of distilled water. Pots were randomly distributed in the greenhouse, with the position changed weekly to avoid any positional effects, and were watered once a week. After 5 weeks, the proportion of disease plants per pot were investigated, To compare the degree of disease in the different treatments, each plant was graded from 0 (no symptoms) to 3 (severe infection) (Clarkson and Cook, 1983) as follows: grade 0: no symptoms of sharp eyespot; grade 1: one or more lesions girdling in total less than half of the stem circumference or one or more lesions on leaf sheath, not penetrating to stem; grade 2: one or more lesions girdling in total at least half of the stem circumference; grade 3: one or more lesions girdling in total at least half of the stem circumference and stem weakened at lesions so that lodging would readily occur. The disease index (DI) was calculated using the formula of Hoilins \& Scott (1983).

$$
\mathrm{DI}=\frac{\sum_{\mathrm{i}=0}^{3}\left(\mathrm{n}_{\mathrm{i}} \times \mathrm{i}\right)}{\sum_{\mathrm{i}=0}^{3}\left(\mathrm{n}_{\mathrm{i}}\right) \times 3} \times 100
$$

Calculated disease index values range from 0 (no symptoms) to 100 (severe infection) ( $i$, severity class and $n_{i}$, number of plants signed to the grade $i$ ). The disease reduced (DR) was calculated using the formula DR (in \%) $=100 \times$ (DI-Control - DI-Treatment)/DI-Control. Each treatment was replicated three times, and all the trials were conducted twice. Analysis of variance was used for statistical analysis. The significance level of $P=0.05$ was used throughout. Multiple range tests were used to compare different treatments. Data from the two trials were combined.

Preparation and purification of the antifungal substance. The endophytic $B$. subtilis EBS05 was cultured in 2 liter of YPD medium at $30^{\circ} \mathrm{C}$ with constant shaking at 170 rpm for $72 \mathrm{~h}$. To remove the bacteria cells and residue, culture broth was centrifuged with $10,000 \times g$ at $4^{\circ} \mathrm{C}$ for 30 min, and the supernatant was acidified to $\mathrm{pH} 2.0$ with conc. $\mathrm{HCl}$ after the formation of precipitate at $4{ }^{\circ} \mathrm{C}$ overnight. The precipitates were collected by centrifugation $(10,000 \times g$, 
$4^{\circ} \mathrm{C}, 15 \mathrm{~min}$ ) and extracted three times with methanol. The methanol was removed with an EYELA rotary evaporator (Tokyo Rikakikai Co. Ltd., Tokyo, Japan) under reduced pressure. The crude biosurfactant was obtained as a lightyellow powder material, and purified by gel filtration on Sephadex LH-20 with methanol as the eluent. Active fractions were pooled and concentrated by evaporator, then purified by silica gel column with chloroform/methanol/ water (65:25:4, by vol.) as the eluent. Further purification was conducted by a reverse-phase high-pressure liquid chromatography system, Agilent 1200 series (Agilent Technologies, USA) equipped with a ZORBAX Eclipse XDB C18 column $(5 \mu \mathrm{m}, 4.6 \times 150 \mathrm{~mm})$ at room temperature. The system was operated at a flow rate of $2.0 \mathrm{ml} / \mathrm{min}$ with $90 \%$ methanol as the mobile phase.

Mass spectrometry analysis. The purified biosurfactant mixture was mixed with an equal volume of matrix solution $(10 \mathrm{mg} / \mathrm{ml} \alpha$-cyano-4-hydroxy-cinnamic acid and matrix in $70 \%$ acetonitrile containing $0.1 \%(\mathrm{v} / \mathrm{v})$ TFA) and the mixture was analyzed on Q-Tof micro system (Waters Corporation, USA). The electro-spray source was operated at a capillary voltage of $32 \mathrm{~V}$, a spray voltage of $5 \mathrm{kV}$ and a capillary temperature of $320^{\circ} \mathrm{C}$.

Antifungal activity assay against Rhizoctonia cerealis. $R$. cerealis strains were provided by the laboratory of Plant Disease Management at the Plant Protection College in Henan Agricultural University and kept on potato dextrose agar (PDA) slants. The 5-day-old mycelia cultured on slants were spread on PDA plates, with $100 \mu 1$ of crude extract (active substance content is about $0.1 \mathrm{mg} / \mathrm{ml}$ ) from endophytic $B$. subtilis EBS05 cultural broth loaded on the plate by stainless steel columns. The plates were incubated at $28^{\circ} \mathrm{C}$ for 5 days and the inhibition zone would appear around the columns containing active substance. $R$. cerealis were inoculated into four flasks containing $40 \mathrm{ml}$ potato dextrose medium to determine the activity against mycelial growth of $R$. cerealis. The crude extract was added into three flasks so that the final active substance concentration were $100 \mu \mathrm{g} / \mathrm{ml}, 50 \mu \mathrm{g} / \mathrm{ml}$ and $25 \mu \mathrm{g} / \mathrm{ml}$, respectively, and the flask that did not contain any active substance was used as a control. Four flasks were incubated at $28^{\circ} \mathrm{C}$ with constant shaking at $80 \mathrm{rpm}$ for 5 days and the mycelia growth status of $R$. cerealis was investigated. Each treatment was repeated three times.

\section{Results}

Control of wheat sharp eyespot by endophytic $B$. subtilis EBS05 in greenhouse experiments. Wheat sharp eyespot disease incidence and disease index after the different
Table 1. Control effect of endophytic B. subtilis EBS05 and fungicide fludioxonil on wheat sharp eyespot in greenhouse experiments

\begin{tabular}{lccc}
\hline \hline Treatment & $\begin{array}{c}\text { Disease } \\
\text { incidence (\%) }\end{array}$ & $\begin{array}{c}\text { Disease } \\
\text { index }\end{array}$ & $\begin{array}{c}\text { Disease } \\
\text { reduced (\%) }\end{array}$ \\
\hline Control & $72.0 \mathrm{a}$ & $56.7 \mathrm{a}$ & - \\
Fludioxonil & $36.0 \mathrm{~b}$ & $32.3 \mathrm{~b}$ & 43.0 \\
$\begin{array}{l}\text { Ferment broth (cell den- } \\
\left.\text { sities, } 10^{8} \mathrm{cfu} / \mathrm{ml}\right)\end{array}$ & $9.3 \mathrm{c}$ & $5.0 \mathrm{c}$ & 91.2 \\
Filter (bacteria-free) & $10.7 \mathrm{c}$ & $6.7 \mathrm{c}$ & 88.2 \\
\hline
\end{tabular}

Note: Different letters within columns indicate a significant difference, while the same letters denote non-difference $(p<0.05)$

treatments were assessed in greenhouse experiments. Disease incidence and disease index of wheat plants of the control were significantly higher than the values obtained from the endophytic B. subtilis EBS05 and a fungicide fludioxonil treatment (Table 1). Based on the disease index, after fermentation broth, bacteria-free filter and fludioxonil treatment, wheat sharp eyespot disease was reduced by $91.2 \%, 88.2 \%$ and $43.0 \%$, respectively, compared to the inoculated control plants. Application of the culture broth of endophytic B. subtilis EBS05 proved to be significantly more effective at controlling wheat sharp eyespot disease compared with the treatment with fludioxonil. It was therefore suggested that the active substance secreted by endophytic B. subtilis EBS05 played a major role in wheat sharp eyespot disease suppression (Asaka and Shoda, 1996; Yoshida et al., 2001).

Structural analysis of antifungal substances. After purification by reverse-phase high-pressure liquid chromatography, two peaks were observed (data not shown). The second peak exhibited activity against $R$. cerealis in a disk assay. Accordingly, the second peak was further purified and assayed by Q-Tof mass spectrometry. The ESI mass spectrum showed four series of ion peaks at $[\mathrm{M}-\mathrm{H}]^{-}$ $\mathrm{m} / \mathrm{z}=1034.65,1020.64,1006.63$ and 992.65 , and at $[\mathrm{M}+\mathrm{Na}]^{+} \mathrm{m} / \mathrm{z}=1058.66,1044.65,1030.63$ and 1016.62 , respectively (Fig. 1A, B). A set of mass peaks with interval of 14 is often observed for lipopeptides with different numbers of methylene groups $\left(-\mathrm{CH}_{2}-\right)$ in fatty acid chains (Morikawa et al., 2000), which suggests that the purified compounds were surfactin homologues with different carbon chain lengths. Their molecular weights were determined to be 1035.65 Da, 1021.64 Da, 1007.63 Da, and 993.65 Da, respectively, by comparing their mass data with those obtained in previous studies (Lee et al., 2007; Wang et al., 2004).

Each ion peak was selected as precursor ion for further ESI/CID analysis. A series of b- and y-type ions were detected, and a peptide sequence was deducted from this 


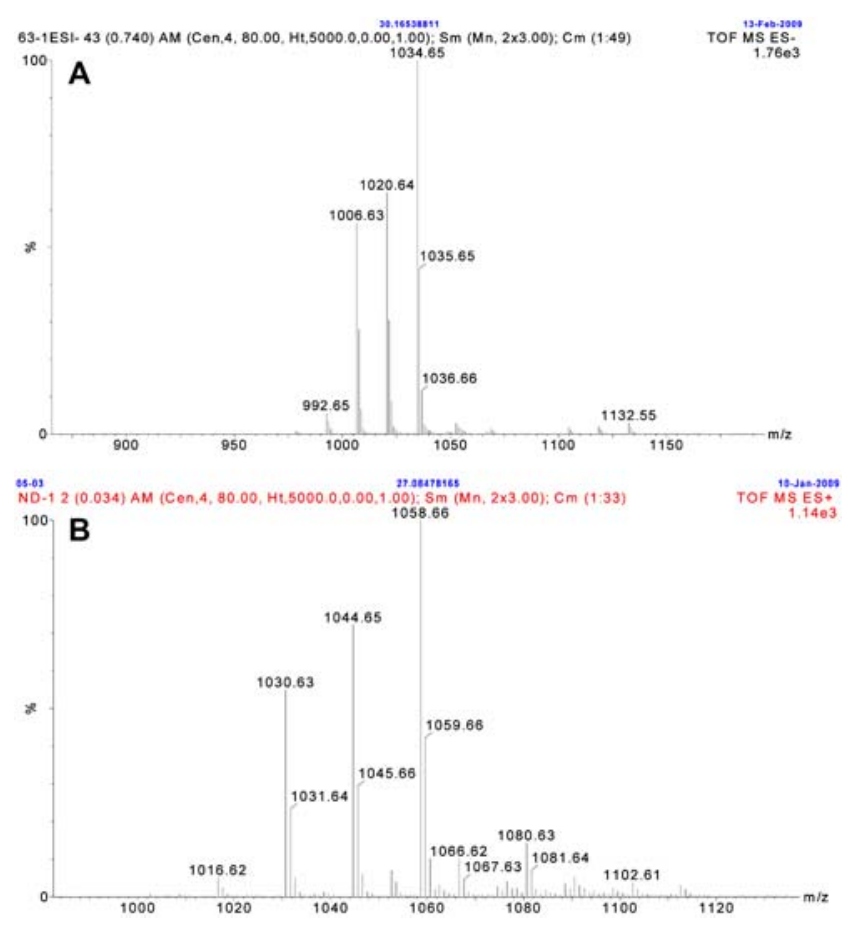

Fig. 1. TOF-MS ES $/ \mathrm{ES}^{-}$mass spectrum of bioactive compound from endophytic B. subtilis EBS05. A and B are ions peaks at $\mathrm{ES}^{-}$ $:[\mathrm{M}-\mathrm{H}]^{-}$and at $\mathrm{ES}^{+}:[\mathrm{M}+\mathrm{Na}]^{+}$, respectively.
CID spectrum by MassBioLynx-Peptide Sequencing. Seven amino acids (Glu-Leu-Leu-Val-Asp-Leu-Leu) were determined by ESI-MS/MS in four precursor ions (figures of ESI-MS-MS spectra of the precursor ion not shown), agreeing with the CID fragmentation of the surfactin standard (Lim et al., 2005; Snook et al., 2009). The patterns of $\mathrm{m} / \mathrm{z} 1058.31[\mathrm{M}+\mathrm{Na}]^{+}$of $\mathrm{y}-\mathrm{Max}$, determined by ESI-MS mass spectrometry, are shown in Fig. 2 as a representative example. The ions at $\mathrm{m} / \mathrm{z} 1040.30$ of $\mathrm{b}-\mathrm{Max}$ found in the spectrum corresponded to losses of $\mathrm{H}_{2} \mathrm{O}(-18 \mathrm{Da})$ from $\mathrm{m} / \mathrm{z}$ 1058.31. Fig. 2 also shows b-ion and y-ion series in accordance with molecular mass and fatty acid-Glu. As constituents of the lipophilic part and peptide of the $\mathrm{m} / \mathrm{z}$ 1058.31, $\beta$-hydroxy-C15 (244.05) and seven amino acids (Glu-Leu-Leu-Val-Asp-Leu-Leu, 813.48) were determined by ESI-MS/MS. According to the double proton transfer mechanism, two protons of the terminal hydroxyl can transfer to its carboxyl terminus in one long peptide when the ester bond is broken. In the lipopeptide, double proton transfer happens in the amino acid residue that expresses the function of carboxyl, and the amino acid residue has more molecular weight (18.01, from 1058.31-1040.30, the molecular weight of $\mathrm{H}_{2} \mathrm{O}$ ) than the fragment that is produced by the breaking of a carbonyl-amine bond. The molecular weight change from 1058.31 to 813.48 indicates

\begin{tabular}{|llllllllll|}
\hline b-ion & 114.09 & 227.18 & 342.20 & 441.27 & 554.36 & 667.44 & 796.48 & 1040.30 \\
& Leu & Leu & Asp & Val & Leu & Leu & Glu & Fatty acid & 244.05 \\
y-ion & 1058.31 & 945.23 & 832.14 & 717.11 & 618.05 & 504.96 & 391.88 & 262.84 & \\
\hline
\end{tabular}

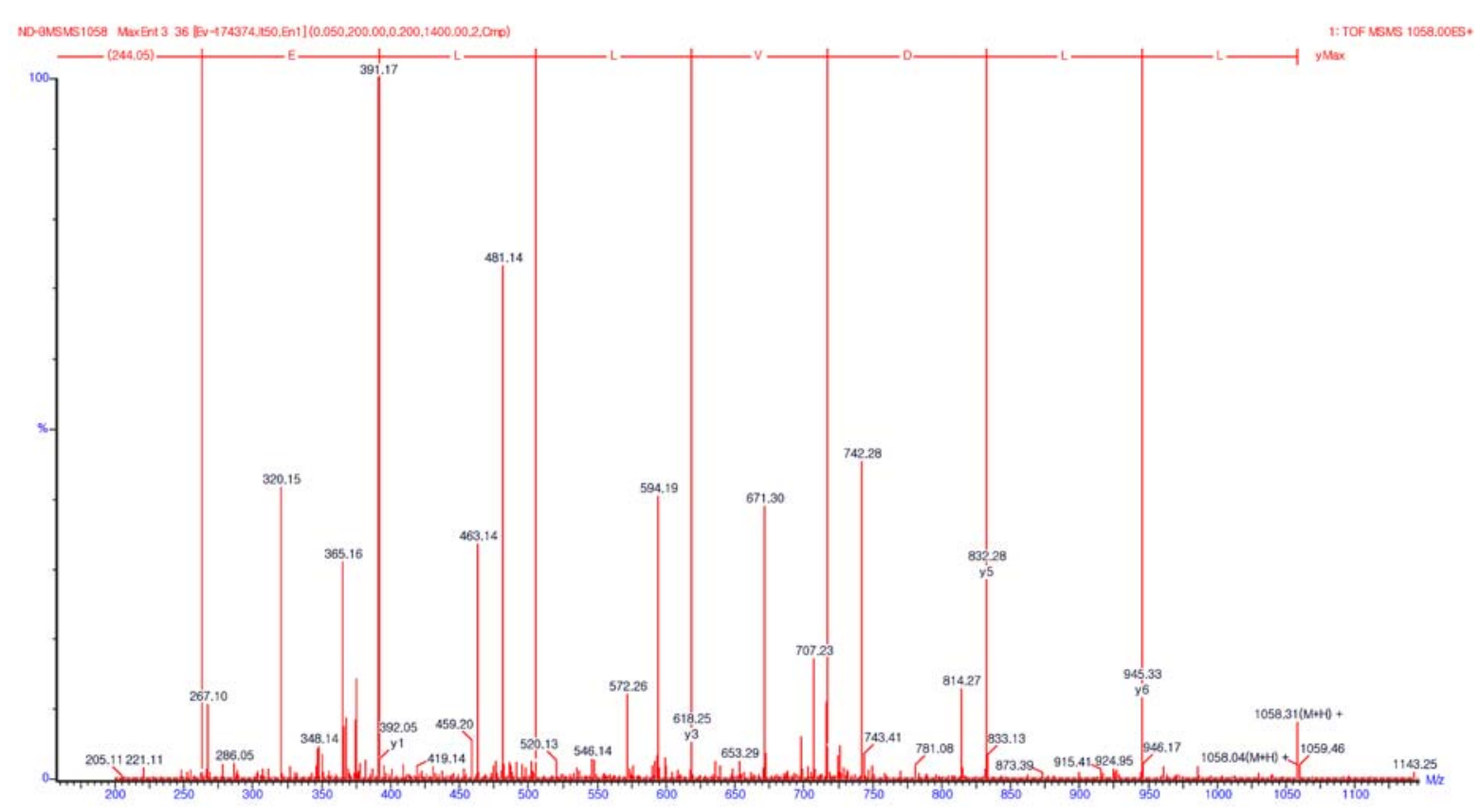

Fig. 2. ESI-MS-MS spectra of the precursor ion m/z 1058.66 from ESI-TOF. 


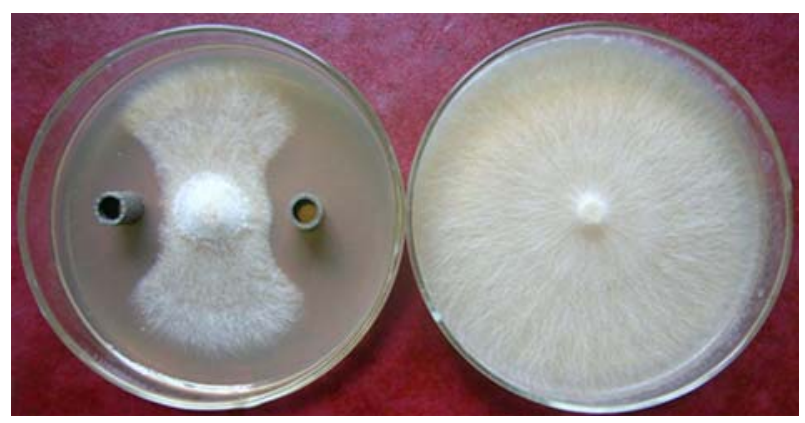

Fig. 3. Inhibition of filtrate from endophytic B. subtilis EBS05 against Rhizoctonia cerealis in PDA plate.

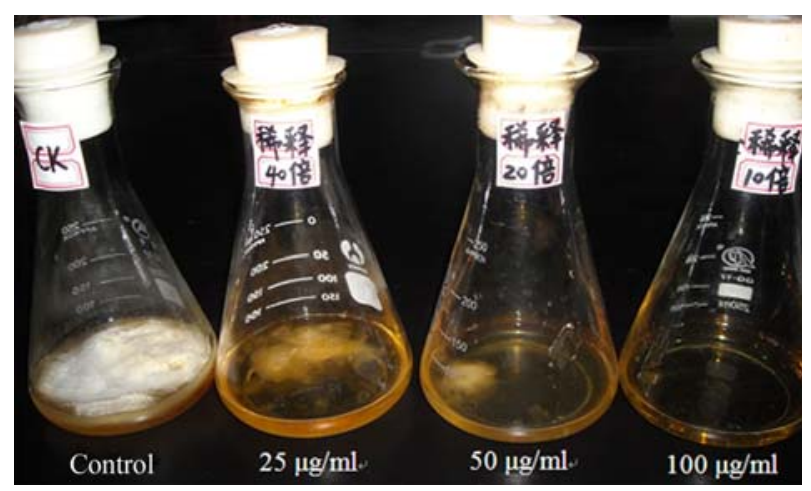

Fig. 4. Inhibition of the active substances from endophytic $B$. subtilis EBS05 against mycelial growth of Rhizoctonia cerealis.

that two Leu and one $\mathrm{H}_{2} \mathrm{O}$ were lost and the inner ester was formed between the Leu and the $\beta$-hydroxy fatty acid moiety, creating a cyclic peptide. Thus, the $\mathrm{m} / \mathrm{z} 1058.31$ $[\mathrm{M}+\mathrm{Na}]^{+}$was identified as $\beta$-hydroxy-C15-Leu ${ }^{7}$-Surfactin. In the same manner, the other lipopeptide structures were determined to be C14-Leu ${ }^{7}$-Surfactin, C13-Leu ${ }^{7}$-Surfactin, and $\mathrm{C} 12-\mathrm{Leu}^{7}$-Surfactin, respectively.

Surfactin is a mixture of closely related cyclic lipopeptide isoforms differing in the length and branching of the fatty acid side chains and in the amino acid substitutions in the peptide ring. Surfactin A, B and C have Leu, Val and Ile, respectively, as the seventh amino acid in the peptide portion of the molecule (Lee et al., 2007; Rodrigues, 2006; Vater et al., 2002). Thus, the active substance produced by endophytic B. subtilis EBS05 is a mixture of the C12 C15 surfactin A isomers.

Antifungal activity of active substance from endophytic B. subtilis EBS05. The in vitro assays showed that endophytic B. subtilis EBS05 exhibited antagonism against some plant pathogens, such as $R$. cerealis, Botrytis cinerea, Fusarium graminearum, Colletetrichum orbiculare, Magnaporthe grisea, F. oxysporum f. sp. cucumerinum, Alternaria alternate, Gaeumannomyces graminis var. tritici, and Pythium aphanidermatum (data not shown). The bacteria- free filtrate strongly inhibited the growth of $R$. cerealis. The inhibitive belt was clearly formed, and the inhibitive rate was about $74 \%$ (Fig. 3). The mycelium growth of $R$. cerealis was inhibited completely by the bacteria-free filtrate when the active substances concentration was 100 $\mu \mathrm{g} / \mathrm{ml}$ in the culture medium (Fig. 4).

\section{Discussion}

Endophytic bacteria are ubiquitous in most plant species and have several beneficial effects on host plants. In addition, they produce a range of natural products that could be harnessed for potential use in medicine, agriculture or industry (Ryan et al., 2008). Specifically, bacterial endophytes colonize an ecological niche similar to that of phytopathogens, which makes them suitable as biocontrol agents (Berg et al., 2006). The bacteria strain EBS05, isolated as an endophyte from $C$. camphora, was identified as $B$. subtilis by morphological taxonomy and sequence analysis of 16S rRNA (GenBank accession no. FJ876834) and $16 \mathrm{~S}-23 \mathrm{~S}$ rRNA intergenic spacer regions (GenBank accession no. DQ538309). Bacillus spp. were present inside various plant tissues in low abundance (Choudhary et al., 2009), and endophytic B. subtilis has been reported as a biological control agent that is effective at suppressing plant disease and promoting plant growth (Liu et al., 2009; Wilhelm et al., 1998; Wulff et al., 2002). In this study, strain EBS05 strongly inhibited in vitro mycelium growth of $R$. cerealis as well as several other plant pathogen fungi. Culture broth (bacteria-free) of endophytic B. subtilis EBS05 was obviously more effective controlling wheat sharp eyespot disease compared with the fungicide fludioxonil. It may be assumed that strain EBS05 exerts effective suppression on wheat sharp eyespot disease through its secondary metabolites.

B. subtilis has been found to have broad suppressive properties for more than 23 types of plant pathogens in vitro due to its ability to produce a high abundance of antibiotics with an amazing variety structures and activities (Stein, 2005; Nagorska et al., 2007). Surfactins, a major fraction of the $B$. subtilis antibiotics, are produced as biological control agents to protect cells from attacks by other microorganisms. Specifically, cyclic lipopeptide surfactins play an important role in biological activities, such as antibacterial, antifungal or antiviral activity (Kim et al., 2009). High antifungal activity by endophytic $B$. subtilis EBS05 is consistent with the known structures of surfactin A isoforms. Standard surfactin, which was originally isolated from a soil strain of B. subtilis, is composed of a macrolide containing the heptapeptide Glu-Leu-Leu-Val-Asp-Leu-Leu and a lipid portion composed of a mixture of several a-hydroxy-fatty acids with a chain length of 13-15 carbon atoms (Lim et al., 
2005). To our knowledge, this is the first report that endophytic $B$. subtilis EBS05 produced C12 C15-Leu ${ }^{7}$ surfactin isoforms that suppressed wheat sharp eyespot disease effectively.

In addition, the endophytic $B$. subtilis EBS05 exhibited strong inhibitory activity against tobacco mosaic virus (TMV) in previous studies (Yin et al., 2009). Cell-free filter extracted from EBS05 culture broth suppressed TMV infection procession in vitro, effectively inhibited TMV replication in vivo and restrained polymerization of the TMV coat protein and interference with the antigen site of TMV. However, very little is known about the mode of action of EBS05 and its surfactin isoforms on suppression of plant fungal and viral pathogens.

Surfactin is one of a few viral antibiotics that is produced by bacteria. Its mode of action is based on its detergent-like activity in dissolving several types of lipid membranes (Snook et al., 2009). B. subtilis strain can modulate host resistance associated with differential gene expression in tomatoes and cucumbers and can trigger the plant defense machinery to enhance resistance to fungal pathogen ingress. Surfactin lipopeptides of B. subtilis, as elicitors, are responsible for the elicitation of the induced systemic resistance (Ongena et al., 2005 and 2007). In our further studies the mechanisms of suppression of both sharp eyespot disease in wheat and TMV in tobacco plants will be investigated.

\section{Acknowledgement}

This work was financed by the Natural Science Foundation of Henan Province, P. R. China (2009B210015).

\section{References}

Asaka, O. and Shoda, M. 1996. Biocontrol of Rhizoctonia solani damping-off of tomato with Bacillus subtilis RB14. Appl. Environ. Microbiol. 62:4081-4085.

Bacon, C. W. and Hinton, D. M. 1999. Use of Bacillus subtilis as an endophyte for the control of disease caused by fungi. Patent 5994117, US Patent and Trademark Office, Nov 30.

Berg, G. and Hartmann, J. 2006. Control of plant pathogenic fungi with bacteria endophytes. In:Schulz B. J. E., Boyle C. J. C., Sieber T N. Microbial Root Endophytes, pp53-69. SpringerVerlag, Berlin.

Bing Liu, Hongping Qiao, Lili Huang, Heinrich Buchenauer, Qingmei Han and Zhengsheng Kang. 2009. Biological control of take-all in wheat by endophytic Bacillus subtilis EIR-j and potential mode of action. Biol. Cont. 49:277-285.

Cindy Lodewyckx, Jaco Vangronsveld, Fiona Porteous, Edward R. B. Moore, Safieh Taghavi, Max Mezgeay and Daniel van der Lelie. 2002. Endophytic bacteria and their potential applications. Crit. Rev. Plant Sci. 21:583-606.

Clarkson, J. D. S. and Cook, R. J. 1983. Effects of sharp eyespot on yield loss in winter wheat. Plant Pathol. 32:421-428.

Devendra K Choudhary and Bhavdish N Johri. 2009. Interactions of Bacillus spp. and plants--with special reference to induced systemic resistance (ISR). Microbiol. Res. 164:493-513.

Ednar G. Wulff, Cames M. Mguni, Carmen N. Mortensen, Chandroo L. Keswani and John Hockenhull. 2002. Biological control of black rot (Xanthomonas campestris pv. campestris) of brassicas with an antagonistic strain of Bacillus subtilis in Zimbabwe. Eur. J. Plant Pathol. 108:317-325.

Eva Wilhelm, Wolfgang Arthofer, Roland Schaeitner and Birgit Krebs. 1998. Bacillus subtilis an endophyte of chestnutt (Castaneasativa) as antagonist against chestnut blight (Cryphonectria parasitica). Plant Cell Tiss. Org. 52:105-108.

Gary Strobel, Bryn Daisy, Uvidelio Castillo and James Harper. 2004. Natural products from endophytic microorganisms. $J$. Nat. Prod. 67:257-268.

Grangemard, I., Peypoux, F., Wallach, J., Das, B. C., Labbe, H., Caille, A., Genest, M., Maget-Dana, R., Ptak, M. and Bonmatin, J. M. 1997. Lipopeptides with improved properties: structure by NMR, purification by HPLC and structure-activity relationships of new isoleucyl-rich surfactins. J. Pept. Sci. 3:145-154.

Hallmann, J., Oualt-Hallmann, A., Mahaffee, W. F. and Kloepper, J. W. 1997. Bacteria endophytes in agricultural crops. Can. J. Microbiol. 43:895-914.

Henis, Y. 1984. Interactions between Sclerotium rolfsii and Trichoderma spp. Relationship between antagonism and disease control. Soil Biol. Biochem. 16:391-395.

Inbar, J. and Chet, I. 1991. Evidence that chitinase production by Aeromonas cabiae is involved in the biological control of soilborne plant pathogens by this bacterium. Soil Biol. Biochem. 23:973-978.

Kim, K. M., Lee, J. Y., Kim, C. K. and Kang, J. S. 2009. Isolation and characterization of surfactin produced by Bacillus polyfermenticus KJS-2. Arch. Pharm. Res. 32:711-715.

Krzysztofa Nagorska, Mariusz Bikwoski and Michal Obuchowski. 2007. Multicellular behaviour and production of a wide variety of toxic substances support usage of Bacillus subtilis as a powerful biocontrol agent. Acta Biochim. Pol. 54:495-508.

Lee, S. C., Kim, S. H., Park, I. H., Chung, S. Y. and Choi, Y. L. 2007. Isolation and structural analysis of bamylocin A, novel lipopeptide from Bacillus amyloliquefaciens LP03 having antagonistic and crude oil-emulsifying activity. Arch. Microbiol. 188:307-312.

Ligia Rodrigues, Ibrahim M. Banat, Jose Teixeira and Rosario Oliveira. 2006. Biosurfactins: potential applications in medicine. J. Antimicrob. Chemoth. 57:609-618.

Lijun Sun, Zhaoxin Lu, Xiaomei Bie, Fengxia Lu and Shengyuan Yang. 2006. Isolation and characterization of a co-producer of fengycins and surfactins, endophytic Bacillus amyloliquefaciens ES-2, from Scutellaria baicalensis Georgi. World J. Microbiol. Biotechnol. 22:1259-1266.

Lim, J. H., Park, B. K., Kim, M. S., Hwang, H. M., Rhee, M. H., Park, S. C. and Yun, H. I. 2005. The anti-thrombotic activity of surfactins. J. Vet. Sci. 6:353-355. 
Marc Ongena, Emmanuel Jourdan, Akram Adam, Michel Paquot, Alain Brans, Bernard Joris, Jean-Louis Arpigny and Philippe Thonart. 2007. Surfactin and fengycin lipopeptides of Bacillus subtilis as elicitors of induced systemic resistance in plants. Environ. Microbiol. 9:1084-1090.

Marc Ongena, Franceline Duby, Emmanuel Jourdan, Thierry Beaudry, Victor Jadin, Jacques Dommes and Philippe Thonart. 2005. Bacillus subtilis M4 decreases plant susceptibility towards fungal pathogens by increasing host resistance associated with differential gene expression. Appl. Microbiol. Biotechnol. 67:692-698.

Martin Kowall, Joachim Vater, Britta Kluge, Torsten Stein, Peter Franke and Dieter Ziessow. 1998. Separation and characterization of surfactin isoforms produced by Bacillus subtilis OKB105. J. Colloid Interf. Sci. 204:1-8.

Maurice E. Snook, Travor Mitchell, Dorothy M. Hinton and Charles W. Bacon. 2009. Isolation and characterization of Leu $^{7}$-surfactin from the endophytic bacterium Bacillus mojavensis RRC 101, a biocontrol agent for Fusarium verticillioides. J. Agric. Food Chem. 57:4287-4292.

Misaghi, I. and Donndelinger, C. R. 1990. Endophytic bacteria in symptom-free cotton plants. Phytopathology 80:808-811.

Morikawa, M., Hirata, Y. and Imanaka, T. 2000. A study on the structure-function relationship of lipopeptide biosurfactants. Biochim. Biophys. Acta 1488:211-218.

Nissen-Meyer, J. and Nes, I. F. 1997. Ribosomally synthesized antimicrobial peptides: their function, structure, biogenesis, and mechanism of action. Arch. Microbiol. 167:67-77.

Peypoux, F. and Michel, G. 1992. Controlled biosynthesis of Val7 and Leu7 surfactin. Appl. Microbiol. Biotechnol. 36:515-517.

Peypoux, F., Bonmatin, J. M. and Wallach, J. 1999. Recent trends in the biochemistry of surfactin. Appl. Microbiol. Biotechnol. 51:553-563.

Phae, G. P., Shoda, S. and Kubota, K. 1990. Suppressive effect of Bacillus subtilis and its products on phytopathogenic microorganisms. J. Ferment. Bioeng. 69:1-7.

Pleban, S., Ingel, F. and Chet, I. 1995. Control of Rhizoctonia solani and Sclerotium rolfsii in the greenhouse using endophytic Bacillus spp. Eur. J. Plant Pathol. 101:665-672.

Robert P. Ryan, Kieran Germaine, Ashley Franks, David J. Ryan and David N. Dowling. 2008. Bacterial endophytes: recent developments and applications. FEMS Microbiol. Lett. 278:19.

Rodrigo Mendes, Aline A. Pizzirani-Kleiner, Welington L. Araujo and Jos M. Raaijmakers. 2007. Diversity of cultivated endophytic bacteria from Sugarcane: Genetic and biochemical characterization of Burkholderia cepacia complex isolates. Appl. Environ. Microbiol. 73:7259-7267.

Schulz, B., Boyle, C., Draeger, S., Rommert, A.-K. and Krohn, K. 2002. Endophytic fungi: a source of novel biologically active secondary metabolites. Mycol. Res. 106:996-1004.

Stein, T. 2005. Bacillus subtilis antibiotics: structures, syntheses and specific functions. Mol. Microbiol. 56:845-857.

Strobel, G. A. 2003. Endophytes as sources of bioactive products. Microbes. Infect. 5:535-544.

Sturz, A. V. and Matheson, B. G. 1996. Populations of endophytic bacteria which influence host-resistance to Erwinia-induced bacterial soft rot in potato tubers. Plant Soil 184:265-271.

Sturz, A. V., Christie, B. R. and Nowak, J. 2000. Bacterial endophytes: potential role in developing sustainable systems of crop production. Crit. Rev. Plant Sci. 19:1-30.

Sturz, A. V., Christie, B. R., Matheson, B. G. and Nowak, J. 1997. Biodiversity of endophytic bacteria which colonize red clover nodules, roots, stems and foliage and their influence on host growth. Biol. Fert. Soils 25:13-19.

Sturz, A. V., Christie, B. R., Matheson, B. G. and Nowak, J. 1997. Biodiversity of endophytic bacteria which colonize red clover nodules, roots, stems and foliage and their influence on host growth. Biol. Fert. Soils 25:13-19.

Sturz, A. V. and Kinpinski, J. 2004. Endoroot bacteria derived from marigolds (Tagetes species) can decrease soil population densities of root-lesion nematodes in the potato root zone. Plant Soil. 262:241-249.

Tan, R. X. and W. X. Zou. 2001. Endophytes: a rich source of functional metabolites. Nat. Prod. Rep. 18:448-459.

Vater, J., Kablitz, B., Wilde, C., Franke, P., Mehta, N. and Cameotra, S. S. 2002. Matrix-assisted laser desorption ionizationtime of flight mass spectrometry of lipopeptide biosurfactins in whole cells and culture filtrates of Bacillus subtilis C-1 isolated from petroleum sludge. Appl. Environ. Microbiol. 68:6210-6219.

Wang, J., Liu, J., Wang, X., Yao, J. and Yu, Z. 2004. Application of electrospray ionization mass spectrometry in rapid typing of fengycin homologues produced by Bacillus subtilis. Lett. Appl. Microbiol. 39:98-102.

Wen, C. Y., Yin, Z. G., Chen, J. G. and Li, H. L. 2009. Identification of endophytic bacteria EBS05 from Cinamonum camphora and property of its antimicrobial compound. Microbiology 36:988-993.

Wilson, D. 1995. Endophyte-The evolution of a term and clarification of its use and definition. Oikos 72:274-276.

Yin, Z. G., Zhao, Y. H., Chen, J. G. and Wen, C. Y. 2009. Primary study on the anti-TMV activity of bioactive substance produced by plant endophytic bacteria EBS05. J. Xiangfan Univ. 30:78-81.

Yoshida, S., Hiradate, S., Tsukamoto, T., Hatakeda, K. and Shirata, A. 2001. Antimicrobial activity of culture filtrate of Bacillus amyloliquefaciens RC-2 isolated from mulberry leaves. Phytopathology 91:181-187. 